\title{
Deal on toxicity law fails to appease
}

\section{MUNICH}

An uneasy compromise has been struck to see Europe's chemical-safety law off the starting blocks. The European Parliament last week gave a preliminary go-ahead to legislation that will bring in extensive toxicity testing of both new and existing chemicals.

But the deal struck during the vote, which would see fewer chemicals tested than originally planned and a drive towards animal-free tests, has left most stakeholders dissatisfied.

The controversial law, known as REACH (Registration, Evaluation and Authorization of Chemicals), is one of the most complicated pieces of legislation that Europe has attempted (see Nature 438, 144-146; 2005). It raises the standards for safety testing of chemicals and puts full responsibility for safety assurance in the hands of industry.

Chemicals produced at levels of more than 1,000 tonnes per year will have to go through a full range of tests that for each compound will cost about $€ 2$ million (US $\$ 2.3$ million) and will use some 4,000 animals.

REACH replaces 1981 legislation that required data on the toxicity of new chemicals to be registered. But its range will also extend to some 30,000 chemicals that were in commercial use before 1981, for which no safety data are currently listed. Most of these compounds will now have to be tested.

IMAGE

UNAVAILABLE FOR COPYRIGHT REASONS

Activists argue that Europe's toxicity tests will kill too many animals.

Since being proposed by the European Commission more than two years ago, REACH has been the focus of intense lobbying, particularly by industry, which argues that it will be too expensive, and by animal-rights supporters, who complain that the testing will cost too many animal lives.

The compromises introduced at the parliamentary reading on 17 November aim to meet some of these objections. Less safety information than planned will now be demanded for compounds in chemical classes that are generally agreed to be non-toxic and are produced in relatively low amounts each year. Of these, any produced at less than 10 tonnes per year will be exempt from all testing.

In response to animal-welfare concerns, the revised law increases the influence of the European Centre for the Validation of Alternative Methods (ECVAM) in approving testing strategies that do not use animals. For example, it gives ECVAM, based in Ispra, Italy, the right to check that a manufacturer is not using animal tests when alternatives exist. And it requires that regulators adopt any alternative test validated by ECVAM within 14 days - something that currently takes months or years.

REACH also obliges industry to share data on safety testing so that each compound is tested only once. A new European Chemicals Agency will be established in Helsinki, Finland, to administer the legislation.

But animal-welfare groups complain that the changes don't go far enough in reducing the number of animals needed for testing. And industry groups maintain that the tests and administration remain prohibitively expensive. Environmental groups, meanwhile, say that the compromises mean that some potentially dangerous chemicals will go untested.

The parliamentary vote is the first step in a process during which the draft law can still be altered. REACH is scheduled for approval next year and should be implemented in 2007. Alison Abbott

\section{China steps up drive to vaccinate all domestic birds}

China claims to be well on the way towards vaccinating every domestic birdin the country againstavianflu. The bold scheme - which would mean inoculating some 14 billion bircs - was announcedon 15 November and comes in response to outbreaks that animal health officials say are dangerously widespread. On 16 November, China confirmedits first two humancases of bird flu, one of which was fatal.

The agricultural ministry says it begana large-scale compulsory vaccination programme in 2004, covering outbreak areas and places considered to be at highrisk. According to a ministry official, some 8 billion birds $(60 \%$ of China's domestic bird population) have already been vaccinated. The use of vaccines in specific areashas successfully reduced the number of outbreaks, says Fusheng Guo, the avian-flu surveillance network coordinator of the Food and Agriculture Organization (FAO) in China.

But Guo says that the number of outbreaks, which reached 17 on 21 November, means that China is approaching an "emergency situation". And that makes mass vaccination even more urgent. "It's a good idea if you can doit properly, with surveillance after wards," Guo says.

Can China complete such a huge programme? Yes, according to Guo, who says that the country's ten vaccine producers can make 16 billion doses of vaccine peryear. If need be, he says, they could double that amount by doubling workers' shifts.

The FAO's senior officer for the Infectious Disease Group in Rome, JuanLubroth, says that China's technology and research in vaccines is top notch - including use of reverse genetics, in which a section of the virus's gene responsible for virulence is removed.

ButLubroth warns that care must be taken tomaintain the quality of the vaccines. "If the vaccine is substandard, you won't get any protection where you think you did." The 'vaccine brigades' mustalso wash clothing and equipment so they don't spread the virus, he says.

There has been scepticism over whether it will be possible to deliver the vaccines to all of the birds kept in small backyard farms. "The logistics of herding in all those loose chickens and ducks is a little more difficult," says Lubroth. But China has proved itself with its belated butimpressive response toSARS, says Guo: "Policemenand soldiers can help in some areas." David Cyranoski 